www.jmscr.igmpublication.org

Index Copernicus Value: 79.54

ISSN (e)-2347-176x ISSN (p) 2455-0450

crossrefDOI: https://dx.doi.org/10.18535/jmscr/v7i3.61

Journal Of Medical Science And Clinical Research

\title{
Rare case of a large pancreatic duct calculus causing pancreatitis
}

Authors

\section{Dr Nandini Venkatesh, Dr P. Surendran, Dr Naveen Alexander}

\section{Introduction}

Chronic pancreatitis is commonly associated with debilitating abdominal pain that may be episodic or continuous. The pathogenesis of pain in chronic pancreatitis is usually multifactorial, pancreatic duct obstruction with resultant ductal hypertension is a relatively common cause. It is also commonly associated with exocrine and/or endocrine insufficiency called fibro-calculus pancreatic diabetes. Pancreatic duct calculi are commonly believed to be a sequela of chronic calcific pancreatitis. Primary pancreatic calculi are commonly seen in main pancreatic duct (wirsung) are usually less than $1 \mathrm{~cm}$ in diameter, irregular and made of calcium salts. Endoscopic and surgical treatments focus on relief of the purported increased ductal pressure. However, endoscopic pancreatic duct stone removal is often difficult due to size or hardness of the stones.

\section{Case Report}

A 52 yr old female patient, known type II diabetic presented with acute abdominal pain radiating to the back for five days duration. The pain was aggravated on food intake. The patient also had non-bilious vomiting of three days duration. Upon further questioning she revealed history of similar episodes of abdominal pain in the past. She gave no history of alcohol intake. On examination her vitals were stable, she was not icteric. On abdominal examination, she had epigastric tenderness with no palpable mass or organomegaly. Blood investigations revealed a moderately elevated amylase and lipase; normal total count; haemoglobin and liver function test. Ultrasonography of the abdomen revealed a grossly dilated main pancreatic duct (MPD) measuring $1.2 \mathrm{~cm}$ with a large calculus within. In view of the dilated pancreatic duct, An MRCP was done which revealed a dilated main pancreatic duct of maximum diameter $3 \mathrm{~cm}$ at the head and $1.1 \mathrm{~cm}$ at the body, proximal part of the duct was grossly dilated with a intraductal calculi measuring $4.7 \times 4 \times 2.5 \mathrm{~cm}$, the accessory pancreatic duct was also dilated with two calculi measuring $18 \times 8 \mathrm{~mm}$ and $8 \times 7 \mathrm{~mm}$.Endoscopic retrograde cholangiopancreatogram (ERCP) was not attempted in view of the large size of the stone. Upper gastroduodenoscopy done was normal. In view of the above findings a surgical plan was formulated, which was discussed with the Patient and consent was obtained from the patient for the planned procedure. Anaesthetic fitness was obtained for the patient preoperatively. The patient was taken up for a upper midlinelaparotomy, proximal pancreatic duct with the large calculus was identified intra-op by localizing the large dilated duct by aspirating with a syringe. The proximal part of the main duct was laid open and a large impacted calculus of size $5 \mathrm{x}$ 


\section{JMSCR Vol||07||Issue||03||Page 337-340||March}

$4 \times 3 \mathrm{~cm}$ was extracted with difficulty from the main duct. Two other smaller calculi from the accessory duct were also removed. This was followed by a lateral pancreatojejunostomy done at a length of $25 \mathrm{~cm}$ from the duodenojejunal flexure. This was followed by fashioning a rouxen-y loop for a jejuno-jejunostomy. Patient was kept in the Intensive care unit post-op on epidural anaesthesia for $48 \mathrm{hrs}$. she recovered well post-op. Her pain reduced considerably and she is doing well on her sixth month follow up with no further recurrent episodes.

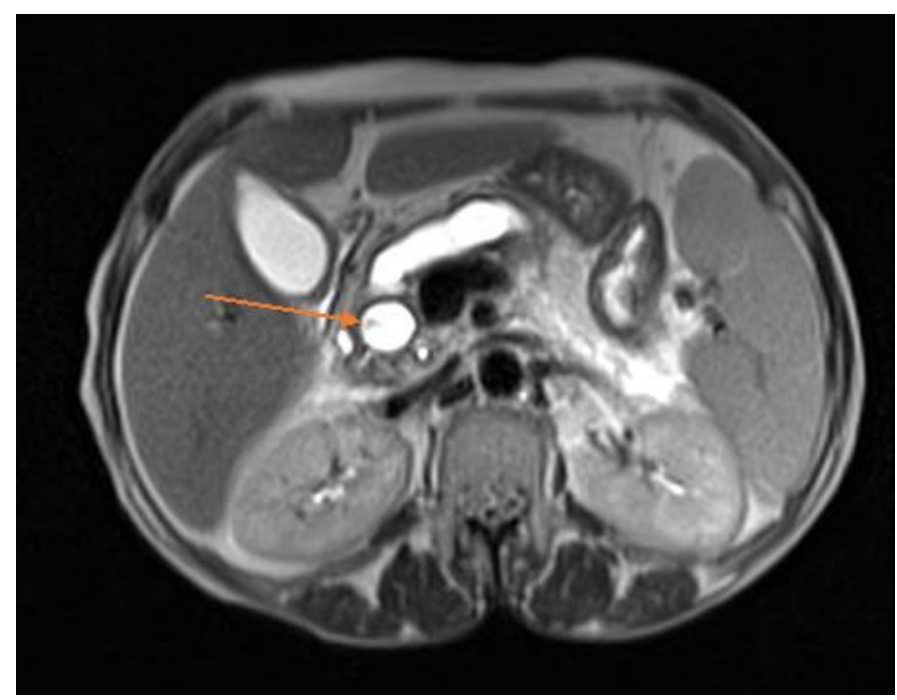

Fig 1 MRCP picture showing the dilated pancreatic duct.

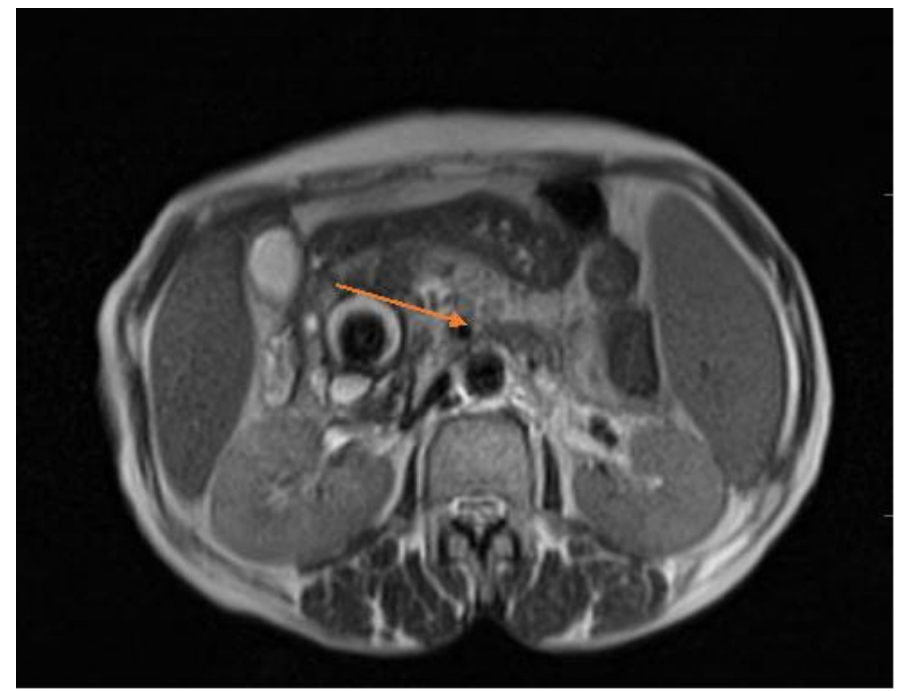

Fig 2 MRCP picture showing large pancreatic duct calculus

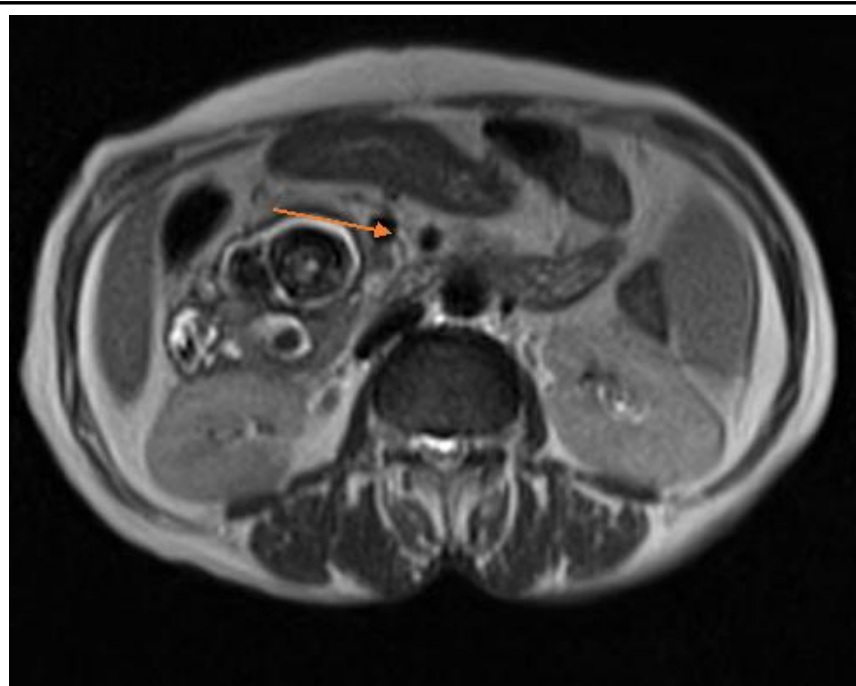

Fig 2 \& Fig 3 MRCP picture showing dilated pancreatic duct with stone.

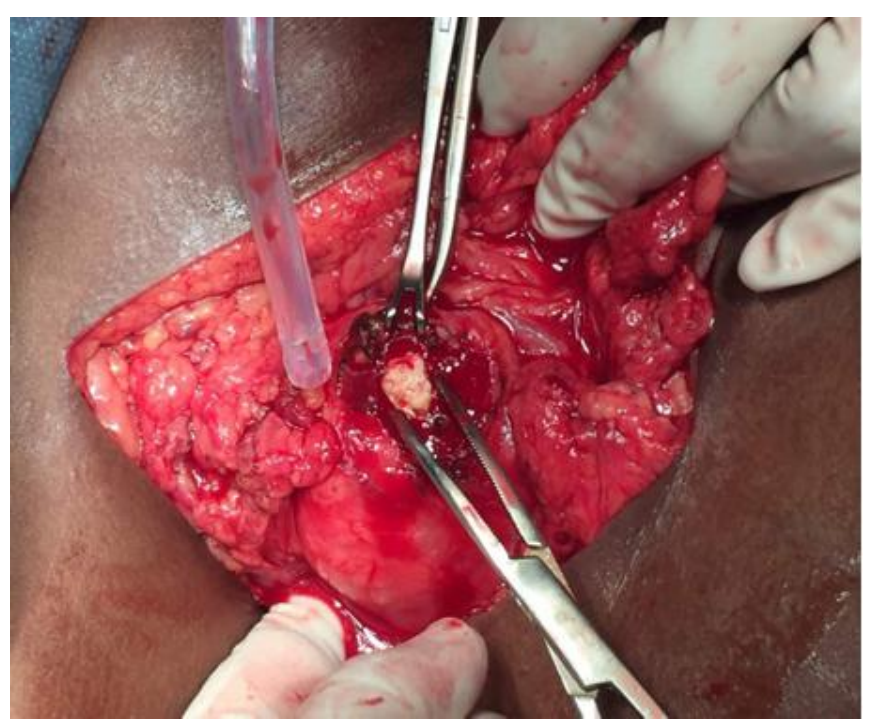

Fig 4 Inta-operative picture of the stone in the pancreatic duct

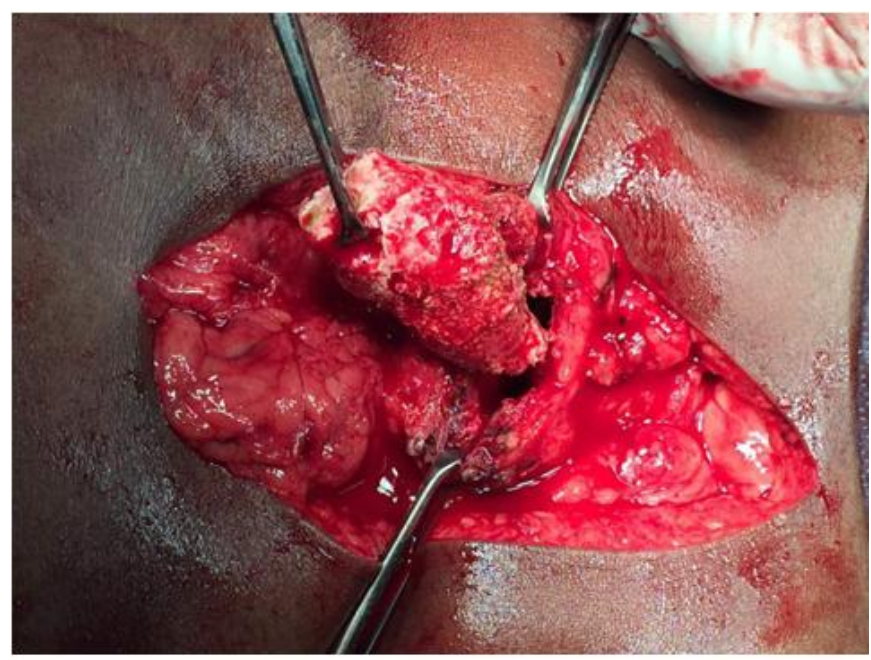

Fig 5 intra-op picture of the stone post extraction from the duct 


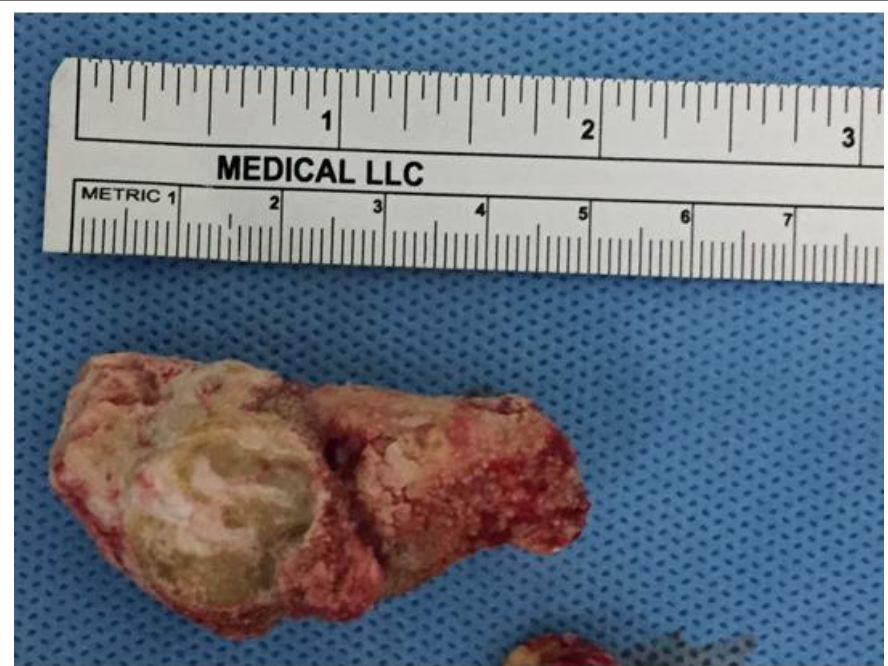

Fig 6 Post-op picture of the pancreatic duct stone

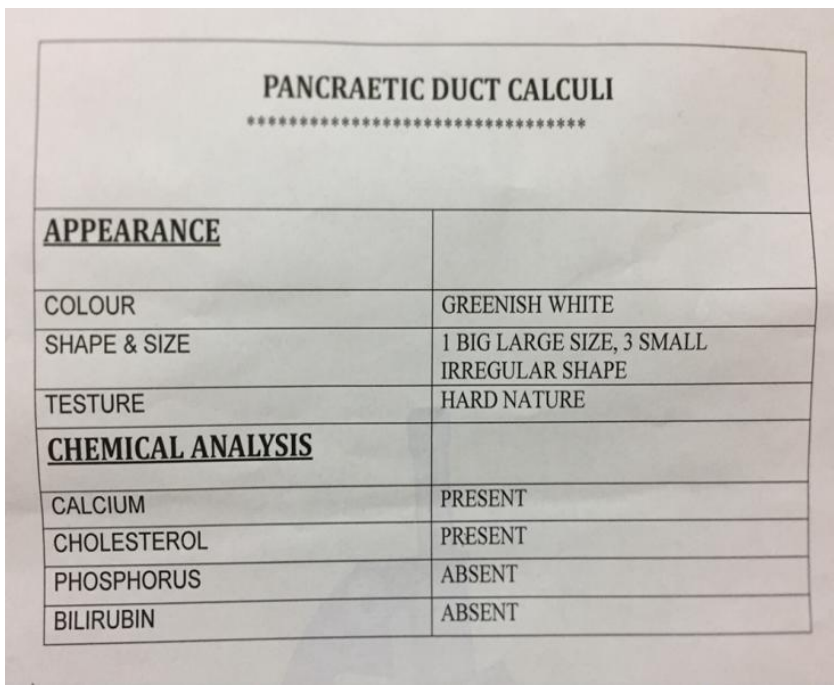

Fig 7 post-op pancreatic duct calculi ananlysis

\section{Discussion}

Pancreatic concretions have been a subject of investigation since the $17^{\text {th }}$ century. Since they were described in 1667 by DeGraaf. ${ }^{[1,2]}$. The first case of pancreatic calculi from India was reported by Kini in $1937^{[9]}$.

Large pancreatic duct calculi and pain are a feature of chronic calcific pancreatitis. Although the exact mechanism is not very clear, the characteristic pathologic changes are well known. Various factors including altered gene expression, cause reduction in the pancreatic stone protein (PSP). As a result of which the ducts become obstructed, due to super saturation of calcium carbonate in the pancreatic juice, that can eventually accumulate. This obstruction results in ductal ectasia and periductal fibrosis. The calculi occur in ducts of all sizes and vary from microscopic to greater than $1 \mathrm{~cm}$ in diameter.

The radiographic appearance is generally that of numerous irregular small calcifications throughout the pancreas. The head of the pancreas is usually involved more prominently than the tail.

Previously, two primary patterns of calcification were believed to exist: an intraductal pattern, representing true stones and a parenchymal calcific pattern, representing "false stones" or calcifications $^{[1,3,4]}$. The current consensus is that the only mode of calcification in the excretory portion of the pancreas is the formation of intraductal calculi ${ }^{[5]}$. In the industrialized nations of the West, alcoholism stands out as the cause for chronic calcific pancreatic disease ${ }^{[1]}$. Tropical pancreatitis is one of the most common causes of $\mathrm{CP}$ in the developing world ${ }^{[6]}$.

In the present case the patient presented with acute on chronic pancreatitis which was not previously evaluated, in whom MRCP revealed a grossly dilated main pancreatic duct with a large calculus at the proximal part of the main duct and two more calculi in the accessory duct. As the calculus was too large and do to the acute nature of presentation endoscopic retrograde cholagiopancreatogram was not attempted.

Endoscopic extraction, with or without extracorporeal shock wave lithotripsy (ESWL), is the preferred method of extraction of MPD calculi $^{[7]}$. However, failing this, transduodenal exploration and calculus extraction from the MPD is a safe procedure.

In the present case due to the non-availability of ESWL and the stone being too large to be removed through a trans-duodenal approach, hence the proximal main pancreatic duct was laid open to extract the large calculi followed by pancreatojejunostomy. For patients with extensive calculi, multiple strictures, a suspected pancreatic carcinoma or those who have failed endotherapy, surgery is considered the better option.

Energy dispersive X-ray fluorescence studies and Electron microscopy have revealed an amorphous nidus which forms the centre of the pancreatic 
duct stone. Calcium carbonate is then deposited in multiple layers as calcite over this nidus ${ }^{[10]}$. In the present case also the pancreatic duct stone analysis revealed irregular stones mainly composed of calcium and cholesterol.

\section{Conclusion}

In conclusion chronic pancreatitis can result in pancreatic duct calculus as a natural sequel of an ongoing process, of which pain may be a dominant symptom. Smaller stones are predominantly dealt with by endoscopic intervention in the form of ERCP by basketing or balloon trawl. Large calculi if present should be subject to ESWL, if successful is followed by ERCP and extraction of the fragmented calculi. These procedures should be performed at experienced centers. Patients with extensive calculi, multiple strictures, suspicious mass lesions and those who have failed endotherapy are ideal candidates for surgery. Removal of existing by any of these above techniques however does not provide answers to many questions. These include recurrence, persistence of pain despite adequate clearance in some patients and the exocrine and endocrine dysfunction, that remain largely unaffected after stone clearance. Further research in these areas is essential in order to provide a final answer to the issues related to pancreatic calculi.

\section{References}

1. Pitchumoni CS, Mohan AT. Pancreatic stones. Gastroenterol Clin North Am 1990; 19:873-93.

2. Rockwern SS, Snively D (citing DeGraaf). Pancreatic lithiasis associated with pancreatic insufficiency and diabetes mellitus. Arch Intern Med 1940; 65:873-5.

3. Lagergren C. Calcium carbonate precipitation in the pancreas, gallstones and urinary calculi. Acta ChirScand 1962; 124:320-5.
4. Mayo JG. Pancreatic calculi. Mayo Clin Proc 1936; 11:456-7.

5. Sarles H, Sahel J. Pathology of chronic calcifying pancreatitis. Am J Gastroenterol 1976; 66:117-39.

6. Geevarghese PJ. Calcific Pancreatitis: Causes and Mechanisms in the Tropics Compared with Those in Subtropics. Trivandrum (Thiruvananthapuram), India: St Joseph's Press, 1986: 67-75.

7. Delhaye M, Matos C, Deviere J. Endoscopic technique for the management of pancreatitis and its complications. Best Pract Res Clin Gastroenterol 2004; 18:155-81.

8. Curry CA, Eng J, Horton KM, et al. CT of primary cystic pancreatic neoplasms: can CT be used for patient triage and treatment? AJR 2000;175:99-103

9. Kini MG. Multiple pancreatic calculi with chronic pancreatitis. $\mathrm{Br} \quad \mathrm{J}$ Surg 1937;25:705.

10. Pitchumoni CS, Viswanathan KV, Gee Varghese PJ, Banks PA. Ultrastructure and elemental composition of human pancreatic calculi. Pancreas. 1987;2:152158. doi: 10.1097/00006676-19870300000005.[PubMed] [CrossRef] 